\title{
eHealth in Norway Before and After the COVID-19 Pandemic
}

\author{
Thomas Schopf ${ }^{1,2}$ \\ ${ }^{1}$ Norwegian Centre for E-health Research, University Hospital of North-Norway, Tromso, Norway \\ ${ }^{2}$ Regional Centre for Asthma, Allergy and Hypersensitivity, University Hospital of North-Norway, Tromso, Norway
}

Corresponding Author:

Thomas Schopf

Norwegian Centre for E-health Research

University Hospital of North-Norway

Sykehusvegen 38

Tromso, 9019

Norway

Phone: 4777626000

Email: Thomas.Schopf@ehealthresearch.no

\section{Abstract}

Background: Regular teledermatology services were implemented in Norway in the early 1990s. Based on the available technology at the time, live interactive video consultation systems were implemented to facilitate remote consultations between dermatologists and general practitioners. With the introduction of digital cameras some years later, store-and-forward systems were introduced, but the live video systems remained popular. In the 2000s and early 2010s, there were few changes in the volume of Norwegian teledermatology services. During the 2010s, private teledermatology companies emerged, which provided both store-and-forward and live interactive video consultations. While previous services involved specialists and general practitioners, the new services now offered to patients enable them to interact with dermatologists directly.

Objective: This lecture aimed to provide a brief overview of the development of telemedicine in Norway before and during the COVID-19 pandemic with special focus on teledermatology.

Methods: This lecture provides a brief history of telemedicine in Norway with special attention to the impact of the ongoing COVID-19 pandemic. The content is based on personal experiences and literature references.

Results: The COVID-19 pandemic has had a profound impact on all parts of society. In Norway, it has also affected the way telemedicine is practiced. When the number of new infections increased substantially in early 2020, Norway was under lockdown. This had major consequences on the health care system. In response, the Norwegian government and health authorities strongly encouraged the use of telemedicine and implemented measures to support its use. Since then, there has been a large increase in the number of live video consultations both in specialist and community health care.

Conclusions: When the necessary technical infrastructure is in place, the remaining barriers to telemedicine use, such as reimbursement and integration of health care systems, can easily be overcome, which would result in high adoption rates of telemedicine.

Conflicts of Interest: TS is a partner of the Norwegian teledermatology provider "Askin."

(iproc 2022;8(1):e36888) doi: $10.2196 / 36888$

\section{KEYWORDS}

COVID-19; pandemic; teledermatology; telemedicine; general practitioner 
Edited by T Derrick; this is a non-peer-reviewed article. Submitted 28.01.22; accepted 28.01.22; published 16.02.22.

Please cite as:

Schopf T

eHealth in Norway Before and After the COVID-19 Pandemic

iproc 2022;8(1):e36888

URL: https://www.iproc.org/2022/1/e36888

doi: $\underline{10.2196 / 36888}$

PMID:

(CThomas Schopf. Originally published in Iproceedings (https://www.iproc.org), 16.02.2022. This is an open-access article distributed under the terms of the Creative Commons Attribution License (https://creativecommons.org/licenses/by/4.0/), which permits unrestricted use, distribution, and reproduction in any medium, provided the original work, first published in Iproceedings, is properly cited. The complete bibliographic information, a link to the original publication on https://www.iproc.org/, as well as this copyright and license information must be included. 